\title{
Pattern effects and noise accumulation in concatenated all-optical regenerators
}

\author{
Lading, Brian; Mørk, Jesper; Bischoff, Svend; Tromborg, Bjarne; Poulsen, Henrik Nørskov
}

Published in:

Summaries of papers presented at the Conference on Lasers and Electro-Optics

Link to article, DOI:

10.1109/CLEO.2001.948128

Publication date:

2001

Document Version

Publisher's PDF, also known as Version of record

Link back to DTU Orbit

Citation $(A P A)$ :

Lading, B., Mørk, J., Bischoff, S., Tromborg, B., \& Poulsen, H. N. (2001). Pattern effects and noise accumulation in concatenated all-optical regenerators. In Summaries of papers presented at the Conference on Lasers and Electro-Optics (pp. 527-528). Opt. Soc. America. https://doi.org/10.1109/CLEO.2001.948128

\section{General rights}

Copyright and moral rights for the publications made accessible in the public portal are retained by the authors and/or other copyright owners and it is a condition of accessing publications that users recognise and abide by the legal requirements associated with these rights.

- Users may download and print one copy of any publication from the public portal for the purpose of private study or research.

- You may not further distribute the material or use it for any profit-making activity or commercial gain

- You may freely distribute the URL identifying the publication in the public portal 


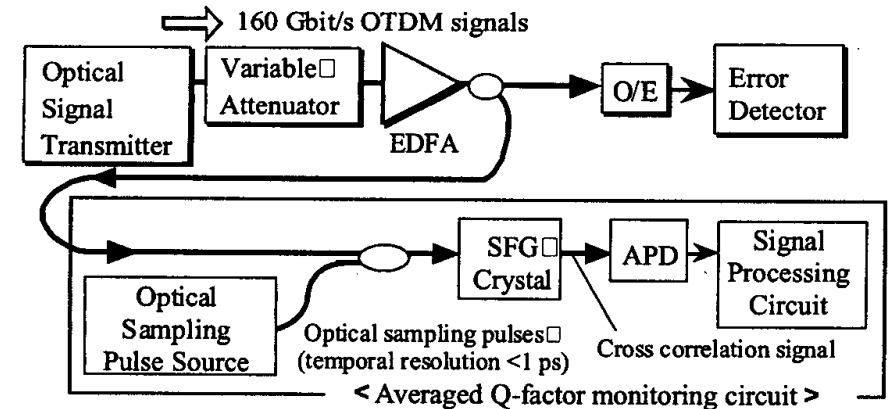

(a)

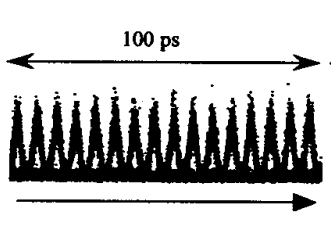

(b)

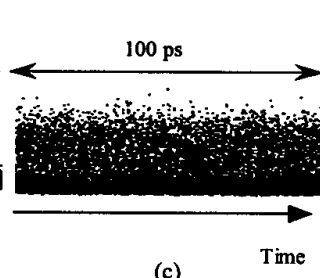

(c)

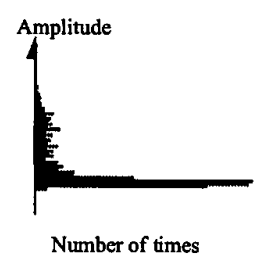

(d)

CThU3 Fig.3. Asynchronous optical signal quality monitoring (a) Experimental setup. (b) Synchronously measured eye-diagram of $160 \mathrm{Gbit} / \mathrm{s}$ OTDM signal. (c) Asynchronously measured eye-diagram and (d) its amplitude histogram.

5. T. Morioka et al., Electron. Lett., 30, 1166 (1994).

6. H. Takara et al., Electron. Lett., 35, 1263 (1999).

7. K. Uchiyama et al., IEEE Photon. Technol. Lett., 12, 915 (2000)

8. H. Takara et al., Electron. Lett., 32, 1399 (1996).

9. I. Shake et al., submitted to Electron. Lett.

\section{CThU4}

$5: 45$ pm

\section{Pattern effects and nolse accumulation in} concatenated all-optical regenerators

B. Lading, J. Mørk, S. Bischoff, B. Tromborg, H.N. Poulsen, Research Center COM, Technical University of Denmark, Bldg. 345v, DK-2800, Lyngby, Denmark; e-mail:bla@com.dtu.dk

In future high-speed networks, interferometric structures based on semiconductor optical amplifiers (SOAs) are strong candidates for wavelength conversion applications and signal regeneration. One of the latest reported interferometric devices is the Semiconductor Delayed-Interference Signal-wavelength Converter (DISC), ${ }^{2}$ which allows for high-speed switching by exploiting the fast carrier-depletion related refractive index changes in the SOA.

Here we use a numerical model of the DISC configuration including saturation and dynamical effects in the SOA, to generate pattern dependent transfer functions. These transfer functions are used to evaluate the noise accumulation and the BER of concatenated regenerators in a manner similar to the one proposed in, ${ }^{3}$ but here the analysis is extended to the dynamic case, which becomes very important for bitrates $>10$ $G b / s$. The results are also valid for other interferometric based converters/regenerators.

In the numerical simulations we use a 1500 $\mu m$ long SOA, the input pulse width is 5 ps

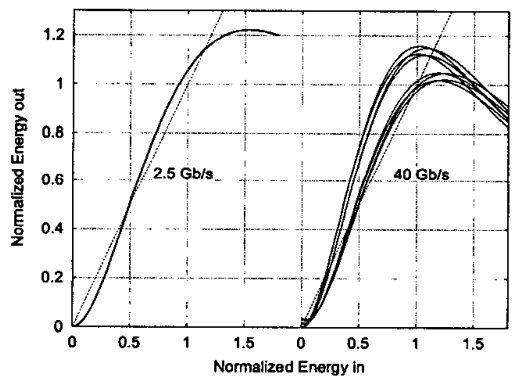

CThU4 Fig. 1. Transfer characteristics for the DISC model. Left plot is for $2.5 \mathrm{~Gb} / \mathrm{s}$ where no pattern effects are visible and right plot is for 40 $\mathrm{Gb} / \mathrm{s}$ where the memory effects of the SOA are clearly visible.

(FWHM, RZ signal) and the signal intensity is adjusted in order to ensure a $\pi$ phase-shift in the SOA. In Fig. 1 we observe the transfer characteristic of the DISC-model at two different bit-rates. The SOA is fast enough to fully recover between pulses at low bitrates. At high bitrates (>10 Gb/s) the SOA no longer recovers fully between bits, causing the observed pattern dependent transfer functions.

The evaluation of the transfer functions are done without including noise effects. These are included in the following noise accumulation analysis, where the pattern dependent nonlinear transfer functions are approximated by "staircase" functions made by discrete sets of values $\left\{x_{i}\right\}$. Assuming Gaussian noise, from inline amplifiers and SOAs in the regenerators, added to the signal $\mathbf{s}_{n}=\mathbf{x}_{j}$ before the $n$ 'th node, we calculate a transfer probability matrix $\mathrm{T}$ consisting of the transfer probability elements; $t_{i j}=P\left(s_{n+1}=\right.$ $x_{i} \mid s_{n}=x_{j}$ ). Defining a discrete probability density function (pdf) for the ZERO and ONE signal as $\mathrm{p}_{n}=\left[P\left(s_{n}=x_{1}\right) \ldots P\left(s_{n}=x_{N}\right)\right]^{T}$, we calculate

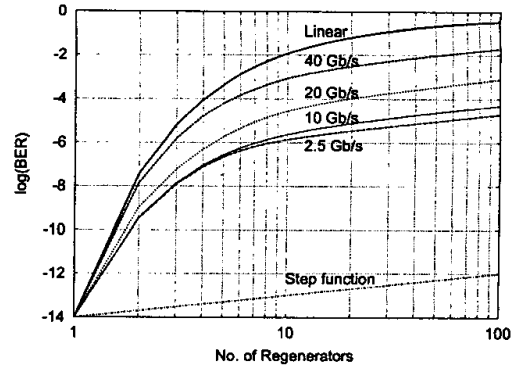

CThU4 Fig. 2. The BER evolution of the system up to 100 concatenated repeaters. The Gaussian noise level is set to give a BER of $10^{-14}$ after one link. Also shown is the BER evolution with a linear- (no regeneration) and a step-function (ideal regeneration) characteristic.

the pdf at node $n$ as $\mathrm{p}_{n}=\mathrm{T}^{n} \cdot \mathrm{p}_{0}{ }^{3}$ The model takes full account of the noise-redistribution, leading to non-Gaussian distribution at the regenerator output.

In Fig. 2 we have plotted the BER as a function of the number of concatenated regenerators at different bit-rates. Pattern effects strongly influence the accumulation of noise at bitrates $>10$ $\mathrm{Gb} / \mathrm{s}$.

The regeneration capability is significantly improved by combining two DISC devices in each node, as done with two MZIs converters in. ${ }^{4}$ This improves the nonlinear transfer characteristics significantly and results in a reduction of the BER by two orders of magnitude, as shown in Fig. 3.

In conclusion, we have extended previous static analyses of noise-redistribution in all-optical regenerators to take dynamical effects into account and shown how pattern effects degrade the regeneration capability at high bitrates.

\section{References}

1. B. Mikkelsen, S.L. Danielsen, C. Jørgensen, R.J.S. Pedersen, H.N. Poulsen and K.E. Stubkjær, "All-optical noise reduction capability of interferometric wavelength converters", Electronics Lett. Vol. 32, No. 6, 1996.

2. Y. Ueno, S. Nakamura, K. Tajima and S. Kitamura, "3.8-Thz Wavelength Conversion of Picosecond Pulses Using a Semiconductor Delayed-Interference Signal-Wavelength Converter (DISC)", IEEE Photon. Technol. lett., Vol 10, No 3, 1998.

3. P. Ohlén and E. Berglind, "Noise Accumula-

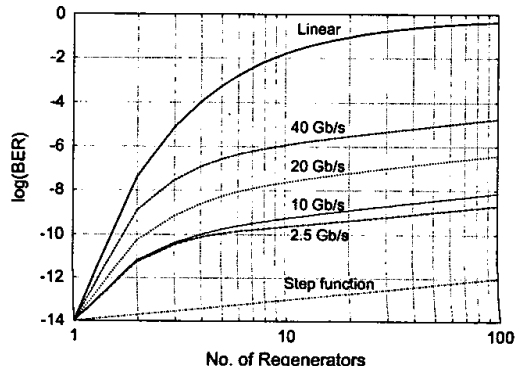

CThU4 Fig. 3. As in figure 2, but this time with two interferometers at each node. Strong improvement of the BER is observed. 
tion and BER Estimates in Concatenated Nonlinear Optoelectronic Repeaters", IEEE Photon. Technol. lett., Vol 9, No 7, 1997.

4. B. Lavigne, D. Chiaroni, P. Guerber, L. Hamon and A. Jourdan, "Improvement of regeneration capabilities in semiconductor optical amplifier-based 3R regenerators", TuJ3-1 OFC'99.

\section{CThU5}

$6: 00 \mathrm{pm}$

\section{Multiple wavelength demultiplexing using} an ultrafast nonlinear Interferometer

B.S. Robinson, S.A. Hamilton, E.P. Ippen, MIT Lincoln Laboratory, 244 Wood Street, Lexington, MA 02420-9108;E-mail: bsr@mit.edu

Optical rate conversion at user access nodes is a necessity in slotted optical time-division multiplexed (OTDM) networks. Various methods of rate conversion have been previously proposed. For instance, a receiver can optically buffer incoming slots and perform an all-optical rateconversion down to electronic rates. A more practical approach to rate conversion is to consider the incoming slot as $\mathrm{N}$ bit-interleaved OTDM channels which can each be optically demultiplexed, detected, and buffered electronically. Multiple channel demultiplexing has been previously demonstrated in a nonlinear optical loop mirror ${ }^{2}$ and using four-wave mixing in fiber $^{3}$ and a semiconductor optical amplifier. Here, we use the ultrafast nonlinear interferometer $(\mathrm{UNI})^{5}$ to demonstrate multiple wavelength all-optical demultiplexing.

Figure 1 shows the configuration for multiple wavelength demultiplexing using the UNI. In this setup, the aggregate OTDM data stream at a bit rate of $\mathrm{N}^{*} 10 \mathrm{Gbit} / \mathrm{s}$ is used as the control input to the UNI. We use pulse-position modulation (PPM) to eliminate patterning due to gain-saturation effects in the SOA. ${ }^{6}$ The signal input is comprised of $\mathrm{N}$ optical pulse sources at 10 Gbit/s. These sources must be at $\mathrm{N}$ different wavelengths and their pulse widths must be less than the bit period of the aggregate OTDM data stream $(100 \mathrm{ps} / \mathrm{N})$. The $\mathrm{N}$ signal wavelengths are each temporally aligned with successive bit-interleaved OTDM channels on the control input. In this way, the N OTDM channels are wavelength converted to the $\mathrm{N}$ signal wavelengths. At the output of the UNI, the N signal channels are separated using a wavelength division multiplexer (WDM) and electronically processed at 10 Gbit/s.

Experimentally, we have demonstrated multiple wavelength demultiplexing of a $20 \mathrm{Gbit} / \mathrm{s}$ OTDM data stream using the setup shown in Figure 2. The control pulse source is a modelocked fiber laser (MLFL) producing 2 ps pulses at $1545 \mathrm{~nm}$. These pulses are pulse-position modulated (PPM) with a $10 \mathrm{Gbit} / \mathrm{s}$ pseudo-random bit pattern of length $2^{31}-1$. We optically multiplex these pulses to create a $20 \mathrm{Gbit} / \mathrm{s}$ OTDM data stream. Two additional MLFL producing 2 ps pulses at $1550 \mathrm{~nm}$ and $1552 \mathrm{~nm}$ provide the signal pulse sources. The two signal lasers are combined and temporally aligned with the control pulses using optical delay lines (ODL). At the output of the UNI, the two signal wavelengths are filtered and separated. These two outputs are then sent to a $10 \mathrm{Gbit} / \mathrm{s}$ optically preamplified receiver for bit-error-rate (BER) analysis.

Figure 3 shows the results of the bit-error rate tests for multiple wavelength operation. In each of these experiments, the individual signal powers at the input of the UNI are $-5 \mathrm{dBm}$ while the control power is $0 \mathrm{dBm}$. The baseline is measured using the $1545 \mathrm{~nm}$ output directly from the modulator. The unfilled points represent the BER performance of the switch when only a single wavelength is used for demultiplexing while the filled points show the BER performance when both signal wavelengths are used for simultaneous demultiplexing. The maximum observed power penalty for a BER of $10^{-9}$ was $1.5 \mathrm{~dB}$.

In conclusion, we have demonstrated multiple wavelength demultiplexing of a $20 \mathrm{Gbit} / \mathrm{s}$ pulseposition modulated data stream. The interferometric SOA-based switch design requires les

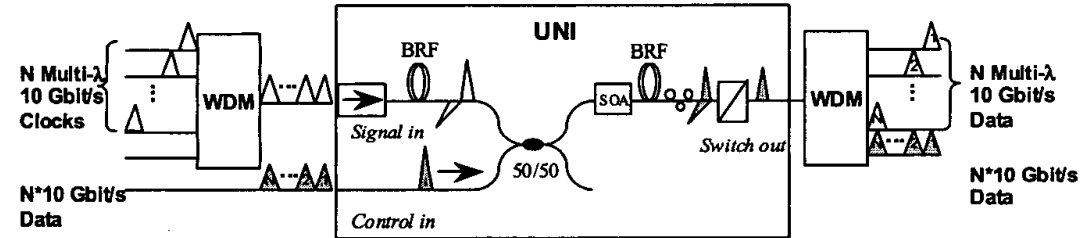

CThU5 Fig. 1. Multiple wavelength demultiplexing with an ultrafast nonlinear interferometer (UNI).

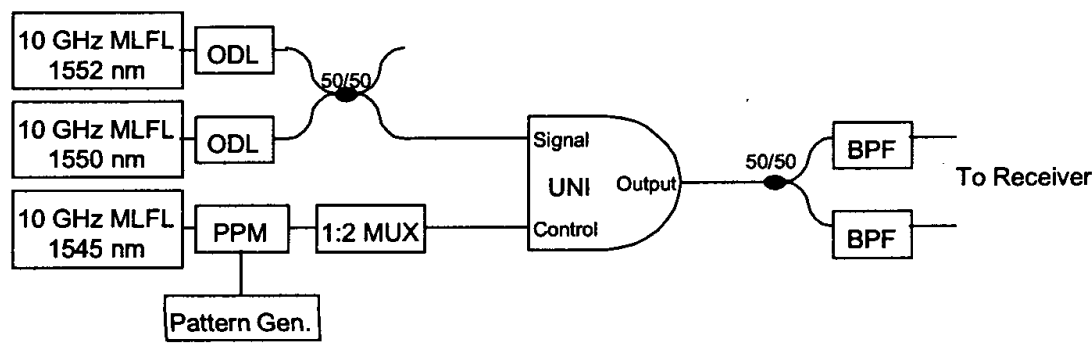

CThU5 Fig. 2. Experimental setup.

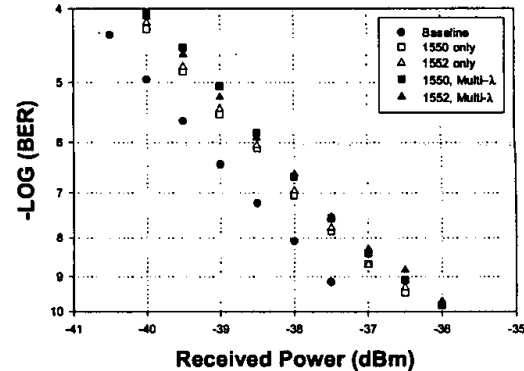

CThU5 Fig. 3. Bit-error rate test results on demultiplexed UNI output.

control pulse power and has less latency than previous work making it an ideal solution for rate conversion in an OTDM receiver. Previous switching results suggest that this technique should readily scale to OTDM data rates of 80 Gbit/s, or more.?

This work is sponsored by DARPA under AF Contract \#F19628-00-C-002. Opinions, interpretations, recommendations and conclusions are those of the author and are not necessarily endorsed by the United States Air Force.

\section{References}

1. N.S. Patel, K.L. Hall, and K.A. Rauschenbach, Opt. Lett., 9, no. 9, p. 1277 (1997).

2. K. Uchiyama, H. Takara, T. Morioka, S Kawanishi and M. Saruwatari, Electron Lett., 32, no. 21, p. 1989 (1996)

3. T. Morioka, S. Kawanishi, H. Takara and $M$ Saruwatari, Electron. Lett., 30, no. 23, p. 1959 (1994)

4. K. Uchiyama, S. Kawanishi, and $M$ Saruwatari, IEEE Photon. Tech. Lett., 10, no. 6, p. 890 (1998).

5. N.S. Patel, K.L. Hall, and K.A. Rauschenbach, Opt. Lett, 21, no. 18, p. 1466 (1996).

6. B.S. Robinson, J.D. Moores, D.T. Moriarty, in CLEO '00 Technical Digest (2000), CPD-19.

7. B.S. Robinson, S.A. Hamilton, E.P. Ippen submitted to OFC'01.

CThV

4:45 pm-6:30 pm Room 321/323

\section{Novel Techniques}

Norman Hodgson, Spectra Physics Lasers, USA, Presider

CThV1

4:45 pm

A novel technique for compensation of birefringence in active elements of solld-state lasers

Efim Khazanov, Institute of Applied Physics, 46 Uljanov st., N. Novgorod, 603600 Russia; email: khazanov@appl.sci-nnov.ru

Heating of active elements (AE) of solid-state lasers gives rise to a thermal lens and birefringence. The problem of how to compensate for the birefringence in $\mathrm{AE}$ has been studied for many years and continues to be a subject of investigation at present. Various designs were sug- 